\title{
Diagnostics of DC and Induction Motors Based on the Analysis of Acoustic Signals
}

\begin{abstract}
A. Glowacz
AGH University of Science and Technology, Faculty of Electrical Engineering, Automatics, Computer Science and Biomedical Engineering, Department of Automatics and Biomedical Engineering, Al. A. Mickiewicza 30, 30-059 Kraków, Poland, adglow@agh.edu.pl

In this paper, a non-invasive method of early fault diagnostics of electric motors was proposed. This method uses acoustic signals generated by electric motors. Essential features were extracted from acoustic signals of motors. A plan of study of acoustic signals of electric motors was proposed. Researches were carried out for faultless induction motor, induction motor with one faulty rotor bar, induction motor with two faulty rotor bars and flawless Direct Current, and Direct Current motor with shorted rotor coils. Researches were carried out for methods of signal processing: log area ratio coefficients, Multiple signal classification, Nearest Neighbor classifier and the Bayes classifier. A pattern creation process was carried out using 40 samples of sound. In the identification process 130 five-second test samples were used. The proposed approach will also reduce the costs of maintenance and the number of faulty motors in the industry.
\end{abstract}

Keywords: Acoustic measurement, electric fault detection, fault diagnosis, maintenance, pattern analysis.

\section{INTRODUCTION}

$\mathrm{N}$ OWADAYS the increased competition in the high availability of production motors causes the formation of new diagnostic techniques. There are some objectives such as: greater competitiveness, safety, cheaper production. These objectives are reached when the produced motors are kept in shape. The examination can be carried out directly after manufacturing, during testing and confirmation as a tool for predictive maintenance as well as for locating any type of flaws. The non-destructive diagnostic methods use physical phenomena as an extension of our senses and a prognosis of the integrity of the machinery, and are performed without interrupting the industrial process [1].

Mechanical and magnetic properties of materials are very essential in diagnostics [2]-[8]. More durable materials mean longer motor life. Nowadays, non-contact measurement systems have been applied in the diagnostics of electrical machines for the detection, localization and assessment of flaws [9]-[10].

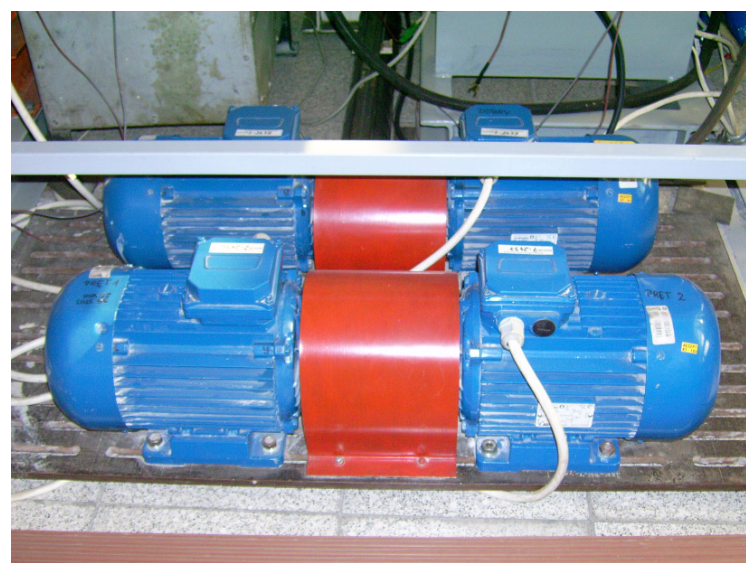

Fig.1. Investigated induction motors.
Diagnostics of faulty machines is related to finding flaws arising in machines. It is essential for rotating machinery. These types of machines are often encountered in mining, fuel production, materials processing, and in the electric power industry. In diagnostics of faulty machines many methods are used for data processing. Some methods are concerned with feature extraction. Other methods deal with classification of processed data. There are also various types of signals used for diagnostics. These signals are the following: magnetic signals, acoustic signals, electric signals, and thermal signals [11]-[15]. In this paper, the research focuses on measurements and recognition of acoustic signals of Direct Current motor and induction motors (Fig.1.). Technical data of motors are in chapters 3 and 4. The results of the research can improve the diagnostics of electric motors.

\section{THE PROCESS OF ACOUSTIC SIGNAL RECOGNITION OF ELECTRIC MOTOR}

The OLYMPUS WS 200S digital voice recorder was used for recording all of the acoustic signals of the electric motors. Soundtracks were recorded with the following parameters: sampling frequency - $44100 \mathrm{~Hz}$, number of channels -1 , number of bits - 16 . The process of acoustic signal recognition of Direct Current motors contained the pattern creation process and the identification process (Fig.2.). At the beginning of the pattern creation process soundtracks were recorded. After that, the data were divided. Next, the signals were normalized and filtrated. Afterwards, the data were converted using the MUSIC method or log area ratio coefficients. In the pattern creation process 20 feature vectors were created. Each vector had 1-8 features. The training step of the Bayes classifier was performed soon afterwards.

The steps of the identification process were similar to the steps of the pattern creation process. Some changes were made in the classification step. In this step the Bayes 
classifier computes the posterior probability of sample belonging to each class. After that the method classifies the test sample according to the higher posterior probability [16]. Acoustic signal recognition has also a second classifier - Nearest Neighbor classifier. This classifier compares feature vectors with each other.

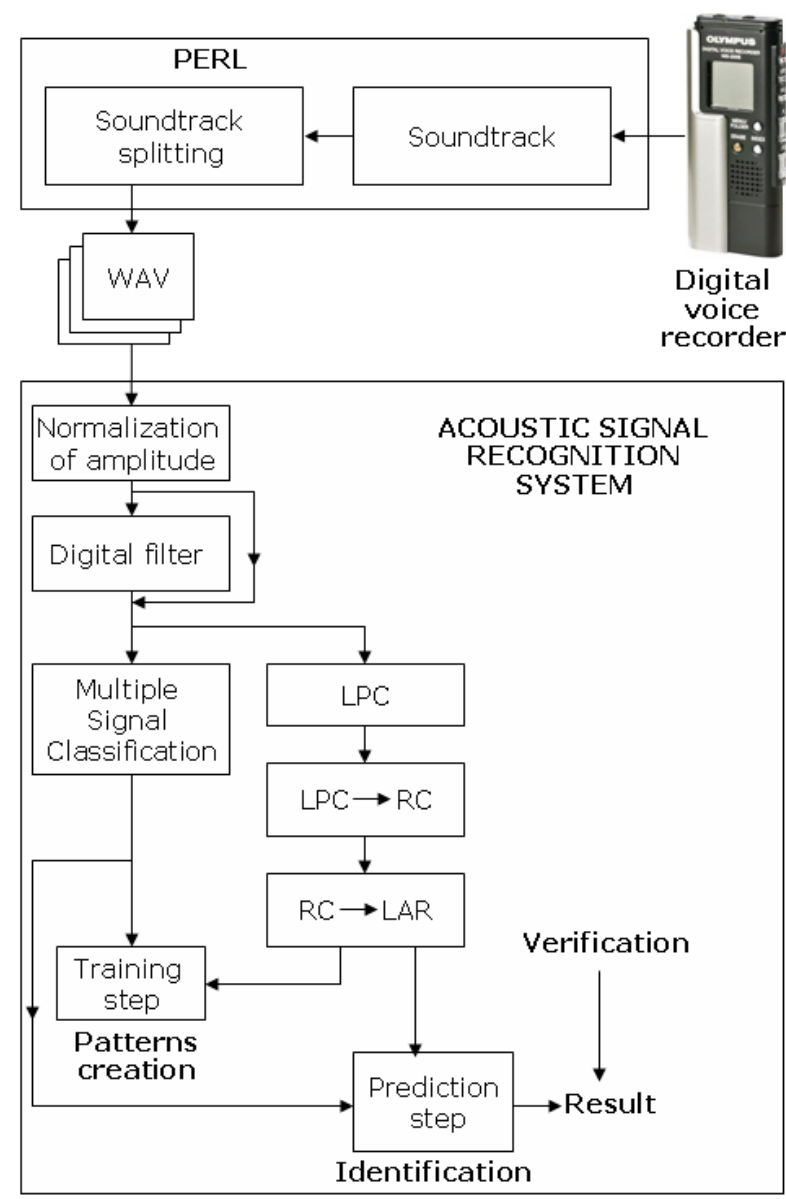

Fig.2. The process of acoustic signal recognition of a Direct Current motor with the use of MUSIC method and the Bayes Classifier

\subsection{Multiple Signal Classification.}

The MUltiple SIgnal Classification (MUSIC) method estimates the pseudospectrum of a signal. It uses Schmidt's eigenspace method. This method performs eigenspace analysis of the signal's correlation matrix [16]. The MUSIC pseudospectrum estimate is defined as follows:

$$
P_{\text {music }}(f)=\frac{1}{\sum_{i=l+1}^{N}\left|\mathbf{v}_{\mathbf{i}}{ }^{H} \mathbf{e}(\mathbf{f})\right|^{2}}
$$

where $\mathbf{v}_{\mathbf{i}}$ is the eigenvector with $i$ index, $N$ is the dimension of the eigenvectors, $l$ is an integer. The eigenvectors $\mathbf{v}_{\mathbf{i}}$ are used in the sum. Complex exponentials are included in the vector $\mathbf{e ( f ) . ~ T h e ~ i n n e r ~ p r o d u c t ~ i s ~ e x p r e s s e d ~ b y ~ f o r m u l a ~ ( 2 ) : ~}$

$$
\mathbf{v}_{\mathbf{i}}{ }^{H} \mathbf{e}(\mathbf{f})
$$

It amounts to a Fourier transform. This is used in order to compute a pseudospectrum estimate. The FFT is computed for each $\mathbf{v}_{\mathbf{i}}$. Next the squared magnitudes are summed. Pseudospectrum estimate is used in the classification step (Fig.3.).

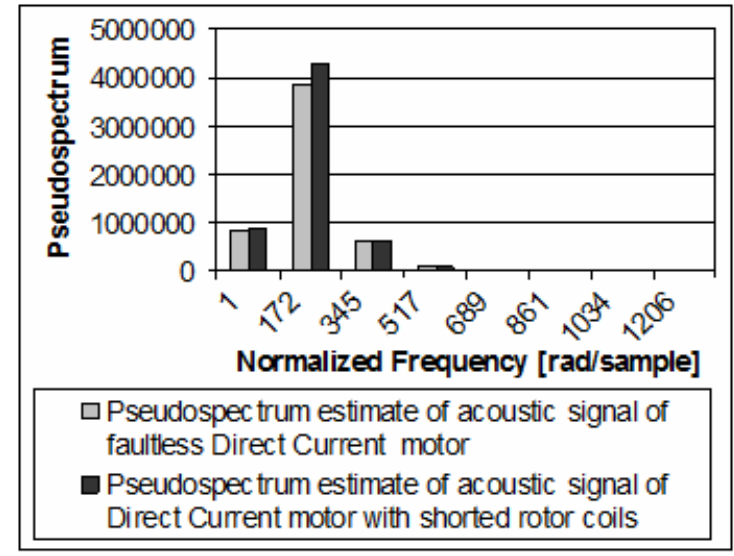

Fig.3. Comparison of pseudospectra estimates of acoustic signals of Direct Current motor after filtration 223-235 Hz.

\subsection{Linear Predictive Coding}

Linear Predictive Coding (LPC) is an approximation of speech production. LPC can be used to analyze the acoustic signals of electrical machines. In this model the throat and mouth form a tube. This coding assumes that an acoustic signal is generated by the tube. The acoustic signal can be also characterized by the frequency and intensity [16], [17]. LPC calculates a set of coefficients. Next, these coefficients form feature vectors. These vectors are used by Nearest Neighbor classifier in the classification step. The coefficients can be used to model the shaping filter. The model of this filter is defined as:

$$
H(z)=\frac{1}{1-\sum_{k=1}^{p} a_{k} z^{-k}}
$$

where $a_{k}$ is the prediction coefficient, $p$ is the order of the filter.

\subsection{Reflection coefficients.}

The reflection coefficients are obtained from the linear prediction coefficients. To obtain these coefficients the acoustic signal recognition system uses the LPC to RC block. This block is based on backward Levinson recursion. The block calculates the $\mathrm{N}$-th reflection coefficient value using the formula $r c_{N}=-a_{N N}$ for $\mathrm{N}$-th order LPC vector $\mathbf{L N}=\left[1, a_{N 1}, a_{N 2}, \ldots, a_{N N}\right]$. After that it finds the lower order LPC vectors, LN-1, LN-2,.., L1 [16], [17]. Next the reflection coefficients are obtained $\left[r c_{1}, r c_{2}, \ldots, r c_{N}\right]$.

\subsection{Log Area Ratio Coefficients.}

The log area ratio coefficients (LAR) are obtained from the reflection coefficients. The LAR model can also characterize the vocal tract of an acoustic signal of machine. 
In LAR analysis, the vocal tract of acoustic signal is modeled as a non-uniform acoustic tube. This tract is comprised of cascading $p$ tubes. Each tube has different cross-section areas with the same lengths. The glottis is connected to the first tube. The last tube is connected to the lips (Fig.4.).

\section{Vocal Tract}

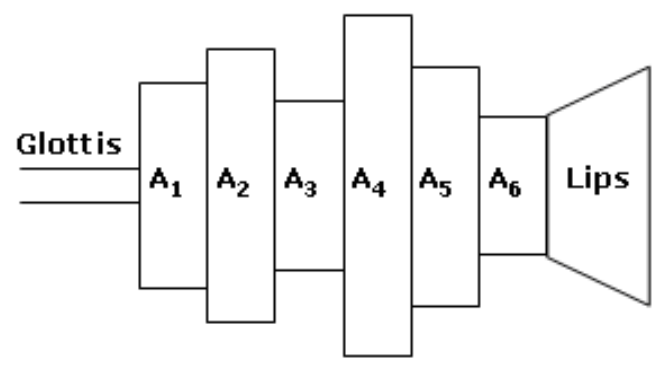

Fig.4. The acoustic tubes of sound production model.

In this approach, the length of each tube depends on the time difference between two sound samples. The log area ratio coefficients are calculated from the cross-section areas of the tubes. The number of LAR coefficients depends on the number of tubes. It is equal to the number of tubes minus 1. The following formula is used to calculate reflection coefficients:

$$
r c_{i}=\frac{A_{i}-A_{i+1}}{A_{i}+A_{i+1}}
$$

The RC to LAR block converts the reflection coefficients to the LAR coefficients [16], [18]. The relationship between the LAR coefficients and the $\mathrm{RC}$ is:

$$
\log \left(g_{i}\right)=\log \left(\frac{1-r c_{i}}{1+r c_{i}}\right)
$$

Absolute values of the log area ratio coefficients are used in the next calculations (Fig.5.).

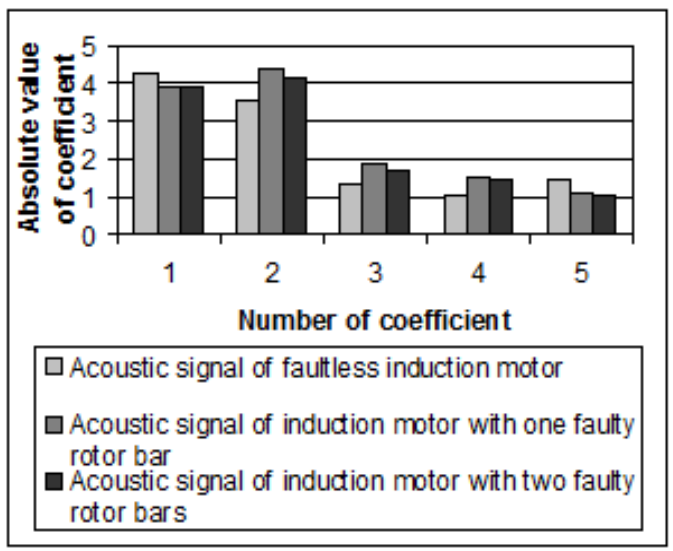

Fig.5. Absolute values of $\log$ area ratio coefficients of acoustic signals of induction motor ( 5 coefficients).

\subsection{The Bayes classifier.}

Many classification and feature extraction methods were developed in literature [19]-[40]. In this approach, the Bayes classifier is used. This classifier uses the Bayes theorem:

$$
p\left(c_{j} \mid d\right)=\frac{p\left(d \mid c_{j}\right) p\left(c_{j}\right)}{p(d)}
$$

where $p\left(c_{j} \mid d\right)$ - probability of instance $d$ being in class $c_{j}$ (Posterior probability); $p\left(d \mid \mathrm{c}_{j}\right)$ - probability of generating instance $d$ given class $c_{j}$; $p\left(c_{j}\right)$ - probability of occurrence of class $c_{j} ; p(d)$ - probability of instance $d$ occurring.

A strong point of this classifier is that it uses a few training samples to estimate the parameters. The method has two steps of classification:

-Training step: the method estimates the parameters of a probability distribution. It uses the training samples.

-Prediction step: Each sample from a test set is processed. The classifier computes the posterior probability of samples. After that the method classifies the test sample according to the higher posterior probability [16].

\subsection{Nearest Neighbor Classifier.}

Nearest Neighbor classifier uses training set and identification set. The method classifies feature vectors based on the nearest training samples. It contains two steps. The training step is following: store every training sample with its label. The prediction step for a test sample is performed as follows: compute its distance to every training sample, next, select the nearest training sample [16]-[18]. Proposed classifier uses test samples to identify the fault of electric motor.

A pattern is a vector of features $\mathbf{s}=\left[s_{1}, s_{2}, \ldots, s_{n}\right]$. Classes of the patterns are defined as $c_{1}, c_{2}, \ldots, c_{J}$, where $J$ denotes the index of the class. Training set has vectors $\mathbf{s}_{\mathbf{1}}, \mathbf{s}_{\mathbf{2}}, \ldots, \mathbf{s}_{\mathbf{j}}$. Identification set has feature vectors $\mathbf{k}_{\mathbf{1}}, \mathbf{k}_{\mathbf{2}}, \ldots, \mathbf{k}_{\mathbf{j}}$. Manhattan distance is used to calculate this distance between vectors. For vectors $\mathbf{s}$ and $\mathbf{k}$ with the same length $n$ it is expressed as follows:

$$
\operatorname{dist}(\mathbf{k}, \mathbf{s})=\sum_{i=1}^{n}\left(\left|k_{i}-s_{i}\right|\right)
$$

where $\mathbf{k}$ and $\mathbf{s}$ are following feature vectors: $\mathbf{k}=\left[k_{1}, k_{2}, \ldots, k_{n}\right], \mathbf{s}=\left[s_{1}, s_{2}, \ldots, s_{n}\right]$.

\section{THE RESULTS OF ACOUSTIC SIGNAL RECOGNITION OF INDUCTION MOTOR}

Researches were carried out for three induction motors with power $P_{N}=500 \mathrm{~W}$. Other parameters were the following: $\quad n_{N}=1400 \mathrm{rpm}, \quad U_{N}=220 / 380 \mathrm{~V} \quad(\Delta / \mathrm{Y})$, $I_{N}=2.52 / 1.47 \mathrm{~A}(\Delta / \mathrm{Y})$, where $n_{N}$ - rotor speed, $U_{n}$ - nominal stator voltage, $I_{n}$ - nominal stator current. Acoustic signals generated by motors were called as follows: acoustic signal of induction motor with two faulty rotor bars (Fig.6.), acoustic signal of induction motor with one faulty rotor bar, acoustic signal of faultless induction motor. Moreover, power supply was $220 \mathrm{~V}, n_{N}=1400$ rounds per minute. 
The pattern creation process was conducted using 20 fivesecond training samples. In the identification process 60 five-second test samples were used. Acoustic signal recognition efficiency was defined:

$$
A S R E=\frac{N o C I T S}{N o A T S} 100 \%
$$

where: ASRE - acoustic signal recognition efficiency, NoCITS - number of correctly identified test samples, NoATS - number of all test samples.

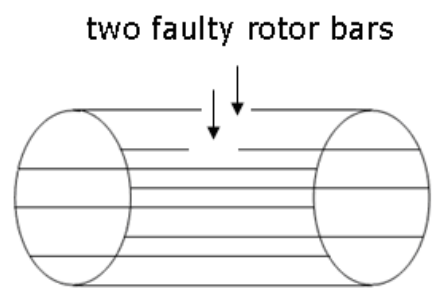

Fig.6. Faulty ring of squirrel-cage of induction motor with two faulty rotor bars.

Fig.7. presents acoustic signal recognition efficiency depending on the number of LAR coefficients.

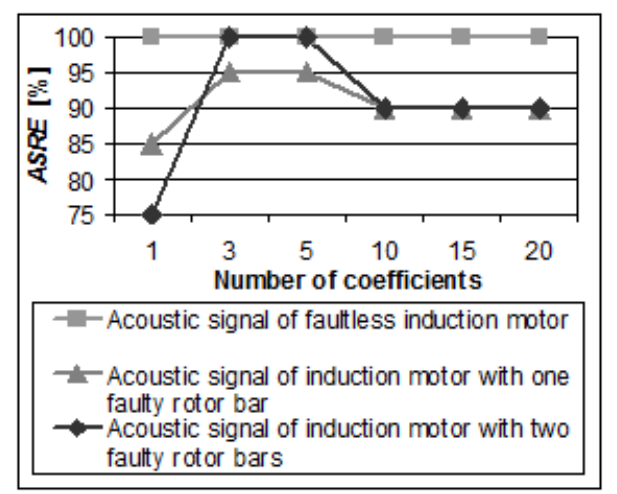

Fig.7. Efficiency of acoustic signal recognition of induction motor depending on number of LAR coefficients.

The best results were obtained for 3 and 5 LAR coefficients. Acoustic signal recognition efficiency was in the range $95-100 \%$. The results of acoustic signal recognition with proposed methods of processing were not as good as the results of current recognition showed in the literature [12] (Efficiency of current recognition $=100 \%$ for each state). The approach based on log area ratio coefficients and Nearest Neighbor classifier can be beneficial for other diagnostic methods of electrical machines.

\section{THE RESULTS OF ACOUSTIC SIGNAL RECOGNITION OF DIRECT CURRENT MOTOR}

The Direct Current motor had the following operation parameters: $P_{N}=13 \mathrm{~kW}, U_{N}=75 \mathrm{~V}, I_{N}=200 \mathrm{~A}, U_{f N}=220$ $\mathrm{V}, I_{f N}=4 \mathrm{~A}, n_{N}=700 \mathrm{rpm}$. Group of three loops of rotor coils was shorted with the help of resistance $R_{b z}=7.7 \mathrm{~m} \Omega$. It was connected with DC machine as external resistance.
This resistance was used to avoid damage of rotor windings. Acoustic signals were analyzed for a flawless Direct Current motor and a Direct Current motor with shorted rotor coils (Fig.8.).

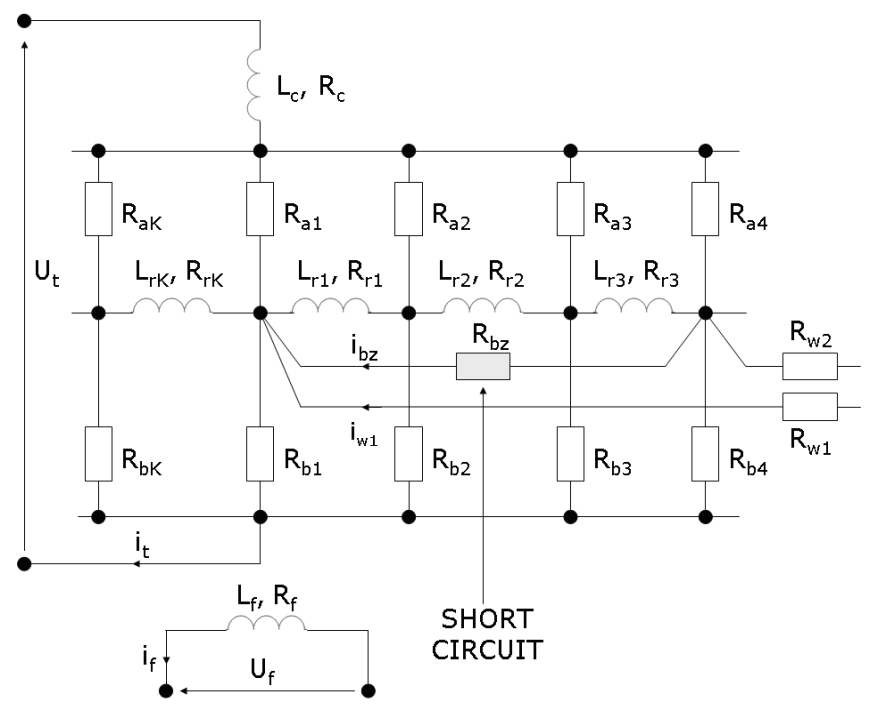

Fig.8. Scheme of rotor winding of Direct Current motor with shorted rotor coils.

Acoustic signals were recorded under laboratory conditions. 10 one-second training samples were used in the pattern creation process for each type of sound. 70 onesecond test samples were used in the identification process. Calculations were conducted for 1-8 features. Following ranges of normalized frequency were investigated: [1-1], [1172], [1-345], [1-517], [1-689], [1-861], [1-1034], [1-1206], [172-172] [rad/sample]. Window size was 256. Very good recognition results were obtained. Digital filter passed frequencies from $223 \mathrm{~Hz}$ to $235 \mathrm{~Hz}$. The range of normalized frequency was [1-172] or [172-172]. The frequencies $223 \mathrm{~Hz}$ to $235 \mathrm{~Hz}$ concerned with the rotation of the rotor $f_{c}=4 X n_{N} \mathrm{~Hz}$, where $X$ was a multiple of the frequency, $n_{N}=700 \mathrm{rpm}$. On the basis of literature of considered 4-pole Direct Current Motor [41], characteristic frequency of current spectrum of shorted rotor coils for mentioned parameters was $46.67 \mathrm{~Hz}(4(700 / 60))$. Author investigated multiple frequencies of $46.67 \mathrm{~Hz}(93.33,140$ etc.). If $X$ was equal 5 , the frequency $f_{c}=(4)(5)(700 / 60)=$ $233.33 \mathrm{~Hz}$ was contained in the frequency range $[223 \mathrm{~Hz}$, $235 \mathrm{~Hz}$. The frequency $223 \mathrm{~Hz}$ was chosen, because there was a possibility of decreasing of the rotor speed. Acoustic signal recognition efficiency of a flawless Direct Current motor was $100 \%$. Acoustic signal recognition efficiency of a Direct Current motor with shorted rotor coils was 71-80\% (Fig.9.).

Moreover, a second method based on acoustic signal recognition was carried out. This method used digital filter, which passed frequencies from 223 to $235 \mathrm{~Hz}$, Multiple Signal Classification and the Nearest Mean classifier. The results of this classifier were better than the results of the Bayes classifier. Acoustic signal recognition efficiency of a flawless Direct Current motor was $97.05 \%$. Acoustic signal recognition efficiency of a Direct Current motor with 
shorted rotor coils was $97.05 \%$. The approach based on the Bayes classifier can be competitive in relation to other diagnostic methods.

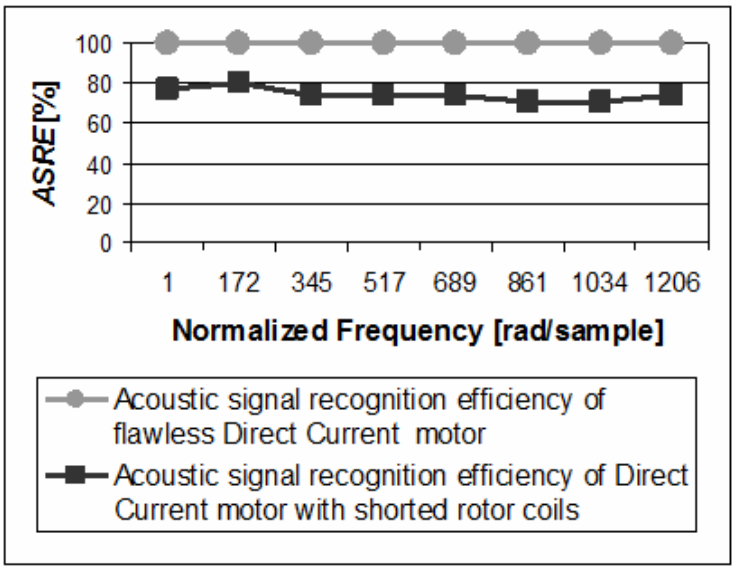

Fig.9. Acoustic signal recognition efficiency depending on the range of normalized frequency.

\section{DISCUSSION}

The first problem for the presented method is the number and types of faults of the electric motor being considered. The results showed that three states of electric motor were recognized properly. The second problem is the number of motors under test. In this paper, DC motor and three induction motors were investigated. Access to industrial electric motors requires cooperation with industry and engineers. A construction scheme of industrial electric motors is also required. Preparations of faults are timeconsuming tasks. The motor load is also one parameter which affects recognition success.

Price is an advantage for the proposed method. Microphone and PC cost about $\$ 400$. All the system needs is a large database of patterns.

\section{CONCLUSIONS}

Electric motor technical condition assessment is a very complex process. Acoustic signals generated by Direct Current motor and induction motors require different signal processing methods to be effective in motor diagnostics. The system based on pattern recognition was proposed and applied to the diagnostics of electric motors. Diagnostic methods were used for detecting and locating flaws. The results of this acoustic signal recognition were sufficient enough. The Bayes classifier had a bit lower efficiency than the Nearest Mean classifier for the same training and test sets. The experimental results proved that the pattern recognition method was effective for condition monitoring of electric motors. Further studies on the use of diagnostics based on acoustic signals may lead to the development of easier and more effective methods of early fault diagnostics of electric motors.

\section{ACKNOWLEDGMENTS}

This work has been supported by AGH University of Science and Technology, grant nr 11.11.120.612.

\section{REFERENCES}

[1] Aastroem, T. (2004). One hundred and one NDT and machine diagnostic methods for the prevention of losses in critical machinery. In 16th WCNDT 2004 : World Conference on NDT. CD-ROM Proceedings.

[2] Gogola, D., Krafcik, A., Strbak, O., Frollo, I. (2013). Magnetic resonance imaging of surgical implants made from weak magnetic materials. Measurement Science Review, 13 (4), 165-168.

[3] Frollo, I., Andris, P., Gogola, D., Pribil, J., Valkovic, L., Szomolanyi, P. (2012). Magnetic field variations near weak magnetic materials studied by magnetic resonance imaging techniques. IEEE Transaction on Magnetics, 48 (8), 2334-2339.

[4] Su, C., Fu, Y.Q. (2014). Reliability assessment for wind turbines considering the influence of wind speed using bayesian network. Eksploatacja i Niezawodnosc - Maintenance and Reliability, 16 (1), 1-8.

[5] Mamala, A., Sciezor, W. (2014). Evaluation of the effect of selected alloying elements on the mechanical and electrical aluminium properties. Archives of Metallurgy and Materials, 59 (1), 413-417.

[6] Tokarski, T., Wzorek, L., Dybiec, H. (2012). Microstructure and plasticity of hot deformed 5083 aluminum alloy produced by rapid solidification and hot extrusion. Archives of Metallurgy and Materials, 57 (4), 1253-1259.

[7] Smalcerz, A. (2013). Aspects of application of industrial robots in metallurgical processes. Archives of Metallurgy and Materials, 58 (1), 203-209.

[8] Kulesza, G., Panek, P., Zieba, P. (2013). Silicon solar cells efficiency improvement by the wet chemical texturization in the $\mathrm{HF} / \mathrm{HNO} /$ diluent solution. Archives of Metallurgy and Materials, 58 (1), 291 295.

[9] Glowacz, A., Glowacz, A., Glowacz, Z. (2014). Recognition of monochrome thermal images of synchronous motor with the application of quadtree decomposition and backpropagation neural network. Eksploatacja $i$ Niezawodnosc - Maintenance and Reliability, 16 (1), 92-96.

[10] Glowacz, A., Glowacz, A., Korohoda, P. (2014). Recognition of monochrome thermal images of synchronous motor with the application of binarization and nearest mean classifier. Archives of Metallurgy and Materials, 59 (1), 31-34.

[11] Glowacz, A. (2014). Diagnostics of synchronous motor based on analysis of acoustic signals with the use of line spectral frequencies and K-nearest neighbor classifier. Archives of Acoustics, 39 (2), 189194.

[12] Glowacz, W. (2013). Diagnostics of induction motor based on spectral analysis of stator current with application of backpropagation neural network. Archives of Metallurgy and Materials, 58 (2), 559562.

[13] Glowacz, Z., Kozik, J. (2013). Detection of synchronous motor inter-turn faults based on spectral analysis of park's vector. Archives of Metallurgy and Materials, 58 (1), 19-23.

[14] Zuber, N., Bajric, R., Sostakov, R. (2014). Gearbox 
faults identification using vibration signal analysis and artificial intelligence methods. Eksploatacja $i$ Niezawodnosc - Maintenance and Reliability, 16 (1), 61-65.

[15] Bajric, R., Zuber, N., Sostakov, R. (2014) Relations between pulverizing process parameters and beater wheel mill vibration for predictive maintenance program setup. Eksploatacja $i$ Niezawodnosc Maintenance and Reliability, 16 (1), 158-163.

[16] MathWorks. (2014). MATLAB and SimuLink for Technical Computing. www.mathworks.com.

[17] Chow, D., Abdulla, W.H. (2004). Speaker identification based on log area ratio and gaussian mixture models in narrow-band speech. In PRICAI 2004 : Trends in Artificial Intelligence. LNCS 3157. Springer, 901-908.

[18] Walendowski, P. (2008). Zastosowanie sieci neuronowych typu SVM do rozpoznawania mowy. Ph.D. Dissertation, Politechnika Wroclawska, Poland.

[19] Kantoch, E., Smolen, M., Augustyniak, P., Kowalski, P. (2011). Wireless body area network system based on ECG and accelerometer pattern. In Computing in Cardiology 2011. IEEE, 245-248.

[20] Kmiec, M., Glowacz, A., Dziech, A. (2012). Towards robust visual knife detection in images: Active appearance models initialised with shape-specific interest points. In Multimedia Communications, Services and Security : 5th International Conference. CCIS 287. Springer, 148-158.

[21] Dudek-Dyduch, E., Tadeusiewicz, R., Horzyk, A. (2009). Neural network adaptation process effectiveness dependent of constant training data availability. Neurocomputing, 72 (13-15), 3138-3149.

[22] Hachaj, T., Ogiela, M.R. (2013). Application of neural networks in detection of abnormal brain perfusion regions. Neurocomputing, 122, 33-42.

[23] Hachaj, T., Ogiela, M.R. (2011). CAD system for automatic analysis of CT perfusion maps. OptoElectronics Review, 19 (1), 95-103.

[24] Ogiela, M.R., Tadeusiewicz, R., Trzupek, M. (2007). Graph-based semantic description in medical knowledge representation and 3D coronary vessels recognition. In Ubiquitous Intelligence and Computing. LNCS 4611. Springer, 1079-1088.

[25] Korohoda, P., Dabrowski, A. (2012). Wavelet-like decomposition stage with windowed filters defined for the Discrete Trigonometric Transforms (DTTs). Przeglad Elektrotechniczny, 88 (6), 30-35.

[26] Skrodzka, E.B., Linde, B.B.J., Krupa, A. (2014). Effect of bass bar tension on modal parameters of a violin's top plate. Archives of Acoustics, 39 (1), 145149.

[27] Jaworek, J., Augustyniak, P. (2011). A cardiac telerehabilitation application for mobile devices. In Computing in Cardiology 2011. IEEE, 241-244.

[28] Dytczak, M., Ginda, G. (2013). Is explicit processing of fuzzy direct influence evaluations in DEMATEL indispensable? Expert Systems with Applications, 40 (12), 5027-5032.

[29] Valis, D., Pietrucha-Urbanik, K. (2014). Utilization of diffusion processes and fuzzy logic for vulnerability assessment. Eksploatacja $i$ Niezawodnosc Maintenance and Reliability, 16 (1), 48-55.

[30] Valis, D., Zak, L., Pokora, O. (2014). Engine residual technical life estimation based on tribo data. Eksploatacja $i$ Niezawodnosc - Maintenance and Reliability, 16 (2), 203-210.

[31] Huang, C.W., Chen, G.M., Yu, H., Bao, Y.Q., Zhao, L. (2013). Speech emotion recognition under white noise. Archives of Acoustics, 38 (4), 457-463.

[32] Augustyniak, P., Smolen, M., Mikrut, Z., Kantoch, E. (2014). Seamless tracing of human behavior using complementary wearable and house-embedded sensors. Sensors, 14 (5), 7831-7856.

[33] Batko, W., Przysucha, B. (2014). Statistical analysis of the equivalent noise level. Archives of Acoustics, 39 (2), 195-198.

[34] Batko, W., Bal, R. (2014). Verification of the calculation assumptions applied to solutions of the acoustic measurements uncertainty. Archives of Acoustics, 39 (2), 199-202.

[35] Knap, M., Falkus, J., Rozman, A., Konopka, K., Lamut, J. (2014). The prediction of hardenability using neural networks. Archives of Metallurgy and Materials, 59 (1), 133-136.

[36] Pleban, D. (2014). Definition and measure of the sound quality of the machine. Archives of Acoustics, 39 (1), 17-23.

[37] Orzechowski, T., Izworski, A., Tadeusiewicz, R., Chmurzynska, K., Radkowski, P., Gatkowska, I. (2005). Processing of pathological changes in speech caused by dysarthria. In Intelligent Signal Processing and Communication Systems (ISPACS 2005). IEEE, 49-52.

[38] Olszewski, R., Trawinski, Z., Wojcik, J., Nowicki, A. (2012). Mathematical and ultrasonographic model of the left ventricle: In vitro studies. Archives of Acoustics, 37 (4), 583-595.

[39] Mazurkiewicz, D. (2014). Computer-aided maintenance and reliability management systems for conveyor belts. Eksploatacja $i$ Niezawodnosc Maintenance and Reliability, 16 (3), 377-382.

[40] Czopek, K. (2012). Cardiac activity based on acoustic signal properties. Acta physica polonica A, 121 (1A), A42-A45.

[41] Zdrojewski, A. (2007) Diagnostyka maszyny komutatorowej pradu stałego bazujaca na analizie spektralnej pomiarowo dostepnych sygnałów. Ph.D. Dissertation. AGH University Science of Technology, Krakow, Poland. http://winntbg.bg.agh.edu.pl/ rozprawy/9972/.

Received February 18, 2014. Accepted September 30, 2014. 